\title{
Investigation of optical laser beam impairment on hypergolic lunarlander exhaust plumes for a lidar feasibility study
}

\author{
Robert Stützer ${ }^{1} \cdot$ Stephan Kraus ${ }^{2} \cdot$ Michael Oschwald $^{1}$
}

Received: 23 October 2019 / Revised: 7 April 2020 / Accepted: 14 April 2020 / Published online: 2 May 2020

(C) The Author(s) 2020

\begin{abstract}
Plumes of two hypergolic bipropellant thrusters of a LunarLander application, developed by ArianeGroup ${ }^{\circledR}$ Lampoldshausen, were optically examined regarding their potential to interfere with laser beams of a nearby LIDAR system. On one hand, hot exhaust gas of a $22 \mathrm{~N}$ Vernier thruster was used to investigate the scattering of a $\lambda=632.8 \mathrm{~nm}$ HeNe laser beam. A series of several engine pulse modes were conducted. An obvious correlation between engine pulse duration and backscattered light intensity is revealed. The shortest pulses result in the most intense backscattering, indicating an incomplete combustion process between the hypergolic constituents $\mathrm{MMH}=$ monomethylhydrazine and $\mathrm{NTO}=(\mathrm{di})$ nitrogen tetroxide for very short pulse lengths. On the other hand, a prolonged pulse mode of $120 \mathrm{~ms}$ firing time causes only marginal deflection of the laser beam. Furthermore, steady operation leads to a negligible signal of backscattered photons, accompanied by increasing emission bands of combustion products such as $\mathrm{CN}, \mathrm{O}_{2}$, and $\mathrm{CO}_{2}$. However, the disappearance of the $\mathrm{OH}^{*}$ emission band, typical for this hypergolic combustion, shows a nearly complete reaction of the hydroxyl radical within the combustor for all pulse modes. Mie scattering calculations show a correlation between the incident laser beam wavelength and the backscattered light intensity. On the other hand, near infrared spectroscopy on the exhaust plume of a $500 \mathrm{~N}$ apogee thruster revealed that interfering flame emission and absorption in the optical range around $\lambda=1064 \mathrm{~nm}$ can be neglected. The relatively intense flame emission measured for $\lambda \geq 1300 \mathrm{~nm}$, on the other hand, is a potential risk for the application of a laser beam of a similar wavelength.
\end{abstract}

Keywords LIDAR $\cdot$ Mie scattering $\cdot$ Spectroscopy $\cdot$ LunarLander

\section{Introduction}

To realize European research projects aiming at moon surface exploration, ESA contracted Airbus Defence \& Space (today: ArianeGroup ${ }^{\circledR}$ ) with a predevelopment study (phase A-B) between 2012 and 2014 on a lunar surface exploration space craft. All engine tests for the LunarLander application were carried out under space and ground conditions on the DLR test site Lampoldshausen, Germany [1]. Due to their space storability, the hypergolic constituents MMH and NTO were used for propulsion, path and position correction as well as for landing maneuvers. A Lidar

Robert Stützer

robert.stuetzer@dlr.de

1 DLR, German Aerospace Center, Space Propulsion, 74239 Hardthausen, Germany

2 ArianeGroup Lampoldshausen, 74239 Hardthausen, Germany system (light detection and ranging), however, is applied to ensure distance and velocity measurements in particular while approaching and landing on the celestial body. Several potential sources of interference must be identified and tested to ensure a sound operation under space conditions. Since the laser beam traverses the exhaust plume during landing maneuver, an error-prone attenuation of the beam intensity can be possible for critical engine parameters such as a high pulse rate with short firing periods and cold thruster structural temperature. Under such conditions, the amount of unburnt particles that leaves the combustor, reaches a critical level and attenuates the incoming laser intensity drastically. Altogether, to sources of unwanted interaction between a laser beam and the plume of a hypergolic driven engine are characterized by: beam impairment by molecular absorption or interference by intense emission bands, and Mie scattering on unburned propellant particles.

The Lidar system itself is mounted on the outer spacecraft casing and beams downward parallel to the main 
thrusters, from where it collects the reflected light out of a cone angle of about $40^{\circ}$. It is planned to use laser wavelengths in the near infrared range of $1064 \mathrm{~nm}$ and $1550 \mathrm{~nm}$. Thus, investigation of emission and absorption behavior of the flame in the NIR spectral range is to be carried out to search the combustion for interfering signals. However, the combustion between the hypergols MMH $\left(\mathrm{CH}_{6} \mathrm{~N}_{2}\right)$ and NTO $\left(\mathrm{N}_{2} \mathrm{O}_{4}\right)$ occurs in the gas phase [2] and therefore depends strongly on pressure and temperature [3]. A detailed description of the reaction between both constituents can be found elsewhere [2]. The ignition time in a combustor on the other hand correlates with the droplet size and thus on the injector geometry as well as on the mass flow rate [4]. Hence, Mie scattering as well as geometric reflection on these pristine fuel particles can disturb the spatial and time coherence of the laser beam. Typical ignition times are in the range of 200-350 ms [4]. All engines of the lander work in pulsed as well as in steady state mode. The pulses will be fired the more frequent the closer the spacecraft is to the moon surface.

Due to their vicinity to the Lidar system, experiments were carried out on a $22 \mathrm{~N}$ Vernier thruster (used for fine adjustment of the space craft), and on a $500 \mathrm{~N}$ apogee thruster (main propulsion and deceleration thruster during the landing phase)

\section{Experimental}

All experiments were carried out at test bench P1.2 of DLR Lampoldshausen, Germany. This test bench is designed for hypergolic thruster tests under vacuum and atmospheric conditions. Altogether, two sources of interference, which a hot exhaust plume represents for laser beams, were investigated. In addition, predictions of Mie scattering effects were developed for these interactions.

\subsection{Light scattering, $22 \mathrm{~N}$ Vernier thruster}

Figure 1 depicts the experimental setup for the Lidar feasibility test on the hot exhaust gas of the $22 \mathrm{~N}$ Vernier thruster under vacuum conditions. At the moment of first ignition, a pressure of $p \approx 10^{-6}$ bar was measured in the chamber. After ignition, the vacuum chamber pressure increased to a nearly constant level of $p \approx 10^{-2}$ bar. Propellant injection was realized by a double swirl injector with an oxidizer/fuel ratio (ROF) of 2.5. To evaluate influences on light scattering intensity regarding engine firing duration, a pulse mode series was applied (see Fig. 2 and Table 1). A commercially available HeNe laser $(\lambda=632.8 \mathrm{~nm})$ that operated in constant wave mode was used as photon source. It was placed outside the vacuum chamber and crossed the plume center before

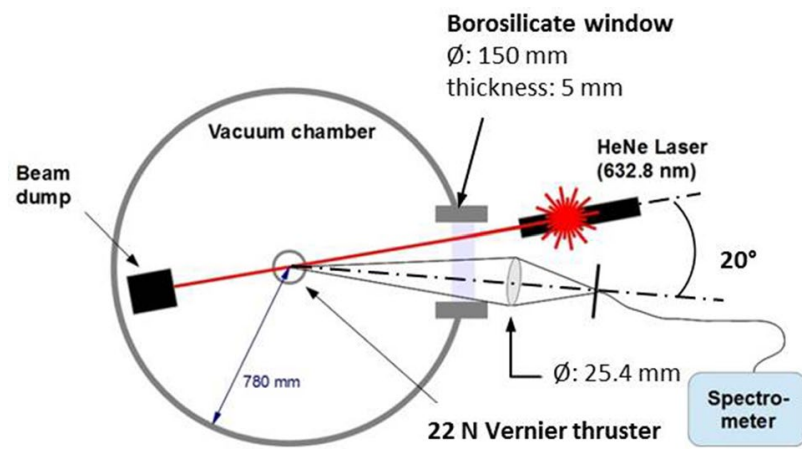

Fig. 1 Top view on the setup for the Lidar feasibility test carried out at test bench P1. The $22 \mathrm{~N}$ Vernier thruster is operated in pulsed mode of several frequencies to study the light scattering behavior of the hot exhaust gas as a function of pulse frequency

being absorbed in a beam dump. A borosilicate window with a thickness of $5 \mathrm{~mm}$ and a diameter of $150 \mathrm{~mm}$ ensured optical entrance into the chamber.

The scattered light was collected using an optical collimator lens ( $\varnothing: 25.4 \mathrm{~mm}, A_{\mathrm{N}} \approx 0.03, f=500 \mathrm{~mm}$ ), focused to the plume-laser-intersection at an angle of $20^{\circ}$ to the laser axis, and from a distance of $800 \mathrm{~mm}$ to the plume axis. The collected light was transmitted via fiber optics to the spectrograph, a Czerny-Turner design model Shamrock 163 from Andor Technology ${ }^{\circledR}$ with a focal length of $163 \mathrm{~mm}$. An iStar720 CCD-camera (Andor) with a resolution of $1024 \times 256$ pixels recorded the incoming signals. All spectra were measured with an exposure time of $10 \times 50 \mathrm{~ms}$. The slit width of $100 \mu \mathrm{m}$ allowed a spectral resolution of 1-2 $\mathrm{nm}$. During test run 1 and 7, the spectrograph shutter was triggered by the operator while the thruster was at a steady state combustion mode. In this case, the shutter alternatingly opened for $50 \mathrm{~ms}$ and was closed for $50 \mathrm{~ms}$ until the total exposure time of $500 \mathrm{~ms}$ was reached. During test run 2-6, the spectrograph shutter was synchronized with the thruster controller. Each initialization signal for a thruster pulse (i.e., the beginning of propellant injection) led to the sending of a trigger signal for the spectrograph. If the shutter was closed, the trigger signal started the spectrograph exposure time (Fig. 2). No delay time between trigger pulse and the opening of the shutter was chosen.

\subsection{Flame emission/absorption, $500 \mathrm{~N}$ Apogee engine}

Experiments on the attenuation and interference behavior of the exhaust plume on a passing laser beam were conducted on a constantly firing $500 \mathrm{~N}$ apogee engine under ambient conditions. Fuel injection took place using a micro showerhead injector. The oxidizer was injected with a pressure level ranging from 14.1 to 21.0 bar. Injection pressure of the fuel 

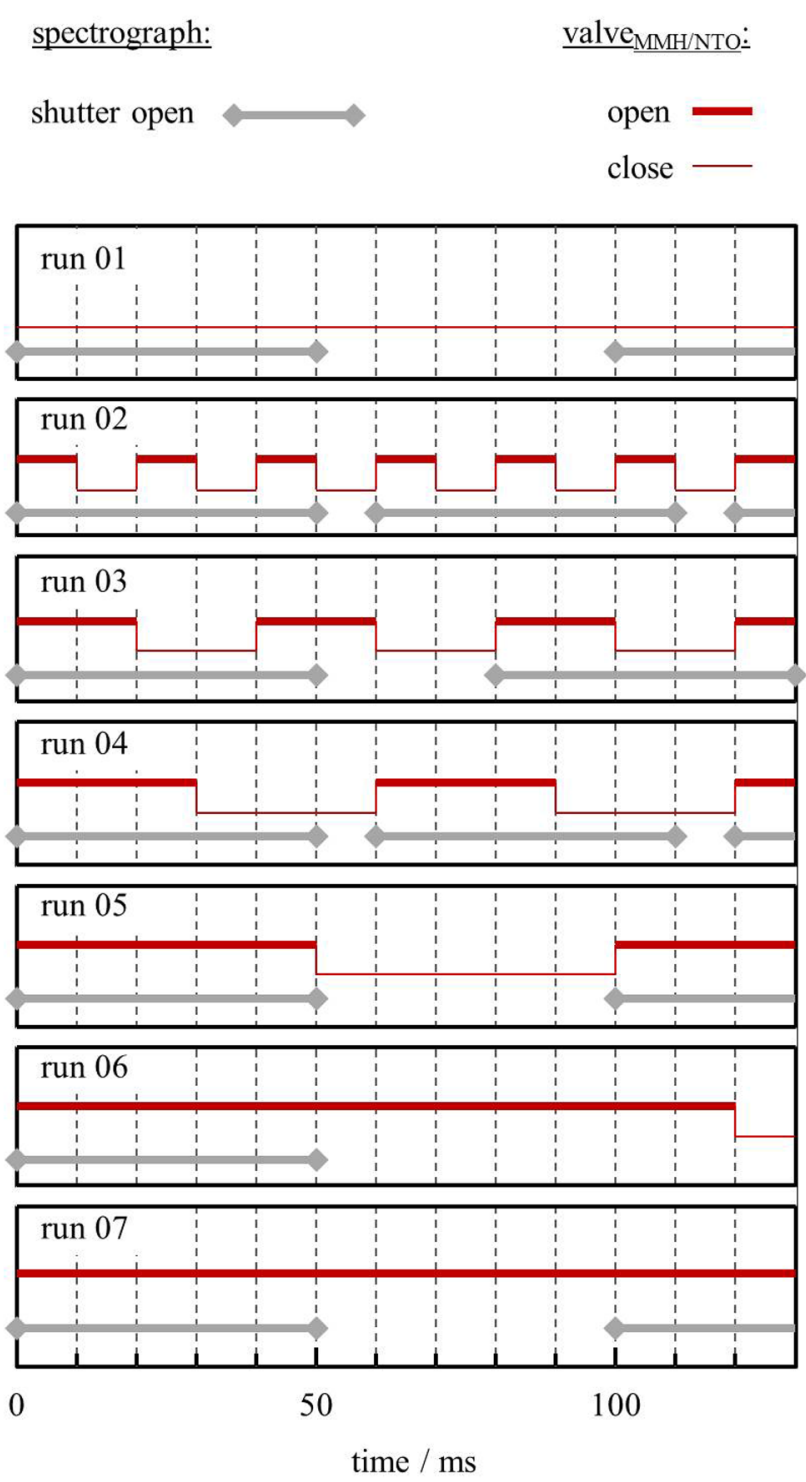

Fig. 2 Time chart (section) of investigated pulse mode sequences of the $22 \mathrm{~N}$ Vernier thruster (red lines) and the associated spectrograph exposure times (grey line)

ranged from 13.6 to 20.15 bar. The oxidizer/fuel ratio was at a constant value of 2.1 .

For optical measurements in the near infrared regime between $900 \mathrm{~nm}$ and $1650 \mathrm{~nm}$ photon wavelength, the
Polytec ${ }^{\circledR}$ PSS 1720 spectrograph with a 256 pixel wide InGaAs detector row was used. With a slit width of $135 \mu \mathrm{m}$, the spectral resolution was $<10 \mathrm{~nm}$. For flame emission measurements, the collimator lens $\left(\varnothing: 25.4 \mathrm{~mm}, A_{\mathrm{N}} \approx 0.03\right.$, $f=500 \mathrm{~mm}$ ) was positioned $1500 \mathrm{~mm}$ from the plume axis. A halogen lamp was placed on the opposite side of the spectrograph's optical collimator with the exhaust plume in between for transmission (absorption) measurements. For both absorption and emission spectroscopy, the optical axis of the collimator was placed $100 \mathrm{~mm}$ underneath the nozzle exit. Each measurement consists of five accumulated single spectra, recorded with an exposure time of $6 \mathrm{~ms}$.

Using the high-resolution transmission (HITRAN) molecular spectroscopic database [5] and its analogue compilation for emission and absorption lines of gases at higher temperatures HITEMP [6], optical spectra were modeled and compared with the experimental data.

\section{Mie scattering model assumptions}

Assuming a spray of droplets with a Sauter mean diameter of $1 \mu \mathrm{m}[7,8]$ and a particle density of 0.1 spheres per cubic $\mu \mathrm{m}$, calculations regarding Mie scattering behavior of the relevant photon wavelengths were carried out using an open source Mie scattering code [9]. Refractive indices $n$ of hydrazine and NTO are wavelength dependent [10]. However, due to lack of reference for $n$ regarding the used laser wavelengths, the refractive indices were estimated and $n=2$ applied.

Since the droplet size was in the range of the applied photon wavelengths of the incident laser beams, Mie scattering theory was chosen over Rayleigh theory [11, 12] since the droplet size was in the range of the applied photon wavelengths of the incident laser beams. The size parameter $a=d / \lambda$ denotes the corresponding laser wavelength: $a(632.8 \mathrm{~nm})=1.58, a(1064 \mathrm{~nm})=0.94$, and $a(1550 \mathrm{~nm})=0.65$.
Table 1 Listed test runs for the Lidar feasibility study

\begin{tabular}{llllllll}
\hline Run & 01 & 02 & 03 & 04 & 05 & 06 & 07 \\
\hline$t_{\text {on }}[\mathrm{ms}]$ & - & 10 & 20 & 30 & 50 & 120 & const. \\
$t_{\text {off }}[\mathrm{ms}]$ & const. & 10 & 20 & 30 & 50 & 80 & - \\
\hline
\end{tabular}

Test run 1 was conducted under quasi-steady-state conditions

During test run 2-6, the thruster worked in pulsed mode applying different frequencies alternating between $t_{\text {on }}$ firing duration and $t_{\text {off }}$ idle time. Run 7 is the control measurement with the thruster entirely switched off 


\section{Results and discussion}

Both optical phenomena with the greatest impact on the Lidar performance were analyzed.

\subsection{Absorption and flame emission}

The visible regime of the $22 \mathrm{~N}$ Vernier thruster plume emission spectrum is shown in Fig. 3. The probing $\mathrm{HeNe}$ laser was switched off while the thruster fired steadily (non-pulsed). On the spectral position of the HeNe laser $(\lambda=632.8 \mathrm{~nm})$, no interfering emission line appears. Furthermore, the lacking $\mathrm{OH}^{*}$ emission band around $\lambda=306 \mathrm{~nm}$ indicates a nearly completed combustion of the reactants outside the combustion chamber [13].

Instead, strong $\mathrm{O}_{2}, \mathrm{CN}$, and $\mathrm{CO}_{2}$ [14] emission bands become visible. Moreover, the sodium line around $\lambda=589 \mathrm{~nm}$, which can be likely found in MMH/NTO spectra, appears only marginally, indicating either an entirely decayed $\mathrm{Na}$ electron shell or a sheer absence of $\mathrm{Na}$. Sodium is used in the MMH synthesis process and cannot be completely removed from the solution. However, the relative brightness of the sodium $\mathrm{D}$ line is a result of high transition probabilities within its electron shell. The proportion of sodium residue in the fuel was determined to be less than $2 \mathrm{mg}$ per $\mathrm{kg} \mathrm{MMH}$.

The dominating $\mathrm{CN}$ emission band at $\lambda=384 \mathrm{~nm}$ [15] was used for intensity comparisons between combustion and backscatter signals. Due to insufficient spectral resolution, a distinction cannot be made between the somewhat overlapping $\mathrm{O}_{2}$ band. However, the $\mathrm{O}_{2}$ emission for this wavelength is negligible compared to the contribution from CN. Data recordings with the engine entirely switched off and the laser beaming show a diminutive signal at $\lambda=633 \mathrm{~nm}$. The used beam dump is thus working not ideally and it is hence necessary to subtract this "zero"-signal from the measurement data.

However, since the LunarLander application will be equipped with laser wavelengths of $1064 \mathrm{~nm}$ and $1550 \mathrm{~nm}$, an emission spectrum has been recorded to reveal possible interferences in the near infrared regime. As depicted in Fig. 4, the plume of a permanently firing $500 \mathrm{~N}$ apogee engine shows a broad $\mathrm{H}_{2} \mathrm{O}$ background between $\lambda=1300 \mathrm{~nm}$ and $1600 \mathrm{~nm}$. In contrast to the spectra of the $22 \mathrm{~N}$ Vernier thruster, strong $\mathrm{OH}^{*}$ radiation $(\lambda \approx 1400 \mathrm{~nm})$ appears in the emission and transmission spectra of the $500 \mathrm{~N}$ engine. This can be described by incomplete combustion and thermal collisions in the exhaust plume. However, the spectral regime around the laser wavelength of $\lambda=1064 \mathrm{~nm}$ is nearly undisturbed and lacks major emission bands.

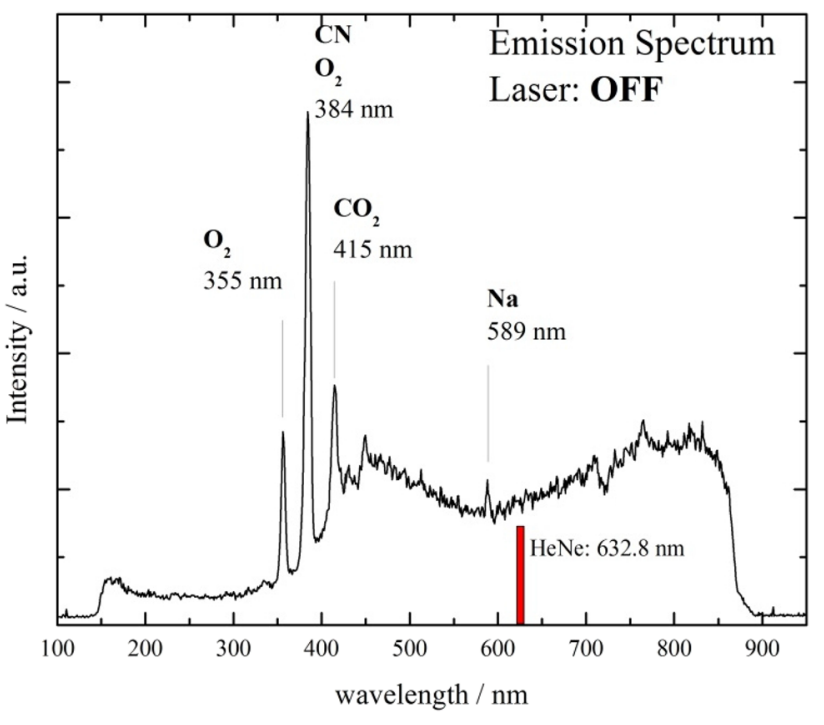

Fig. 3 Plume emission spectrum of the constantly firing $22 \mathrm{~N}$ Vernier thruster (fuel: MMH, oxidizer: NTO). No laser beam was applied and the thruster fired steadily (non-pulsed mode). Prominent emission bands [14] are indicated. No signal interferes with the $\mathrm{HeNe}$ laser wavelength of $632.8 \mathrm{~nm}$. Note the lacking $\mathrm{OH}^{*}$ emission band (306 $\mathrm{nm}$ ) implying the completed reaction of $\mathrm{OH}$-radicals in the plume. Exposure time: $10 \times 50 \mathrm{~ms}$

The experimentally acquired data were analyzed and modelled using HITEMP datasets (Fig. 5). It was found that $\mathrm{H}_{2} \mathrm{O}$ emission lines were in accordance with measured values if a temperature of $1800 \mathrm{~K}$ and a pressure of 1 bar were assumed.

\subsection{Thruster pulse mode-dependent mie scattering}

The first pulse mode to be investigated on the $22 \mathrm{~N}$ thruster was the sequence with a firing time of $10 \mathrm{~ms}$ followed by an idle time of again $10 \mathrm{~ms}$. On a spectral background with a high signal to noise ratio, a distinctive signal can be seen at $632.8 \mathrm{~nm}$ (Fig. 6), indicating a relatively strong backscattering behavior of the plume for short firing times. On the other hand, the emission signals from the combustion itself are only marginally pronounced and disappear in the spectral background.

The pulse mode with the maximum firing time of $120 \mathrm{~ms}$ and an idle time of $80 \mathrm{~ms}$, shows a contrary behavior regarding both the scattered laser signal and the emission originated by the combustion. As depicted in Fig. 7, the Laser, beaming in $\mathrm{CW}$ mode, does not affect the recorded spectrum in the red wavelength regime. On the other hand, the combustion signals between $350 \mathrm{~nm}$ and $490 \mathrm{~nm}$ of the emission spectrum are pronounced over the relatively noisy background. However, the UV-regime lacks entirely emission signals of the $\mathrm{OH}$ radical, typically for this MMH/NTO 


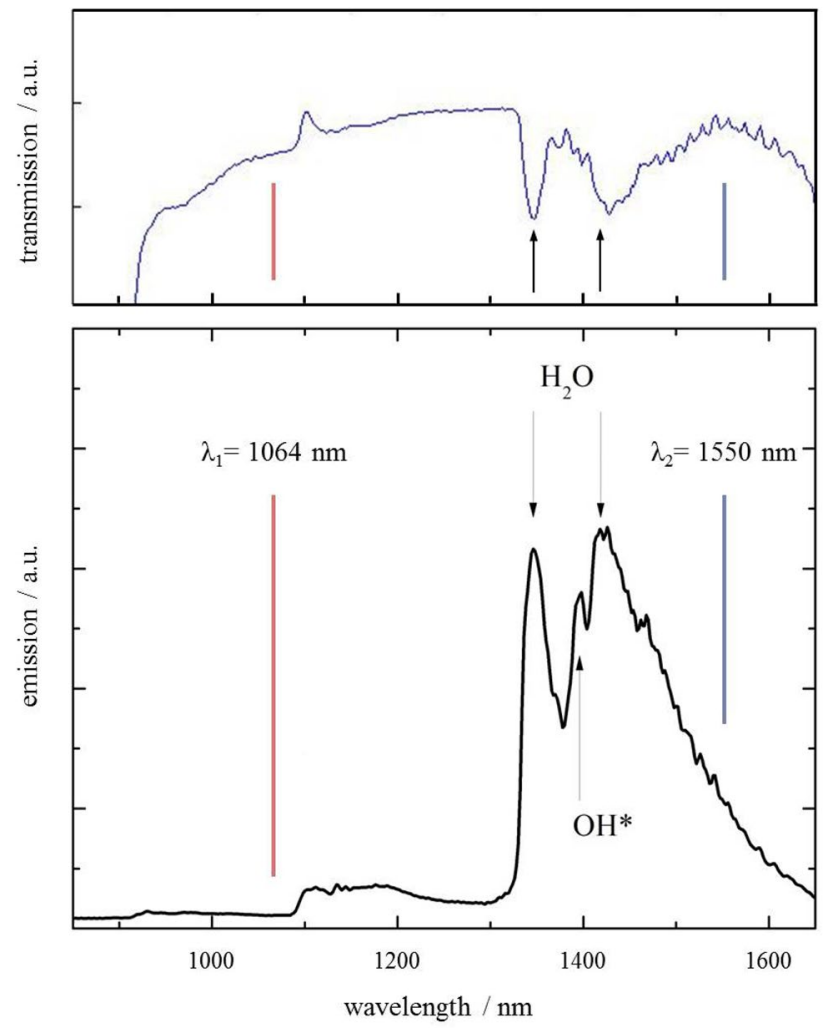

Fig. 4 Near infrared transmission (top) and emission (bottom) spectra, measured on the plume of a MMH/NTO combustion in a $500 \mathrm{~N}$ LunarLander engine. Both laser wavelengths of the Lidar system are depicted $\left(\lambda_{1}\right.$ and $\left.\lambda_{2}\right)$. Relatively intense molecular bands of $\mathrm{H}_{2} \mathrm{O}$ and HO* [14] appear in the $\lambda>1300 \mathrm{~nm}$ range

combustion. Exposure time on the detector was an accumulation of ten times $50 \mathrm{~ms}$.

Figure 8 shows the normalized intensity ratio of the backscattered laser light $(\lambda=632.8 \mathrm{~nm})$ and the $\mathrm{CN}$ emission band $(\lambda=384.0 \mathrm{~nm})$ as a function of thruster pulse duration. The $\mathrm{CN}$ emission band is the most intense sign

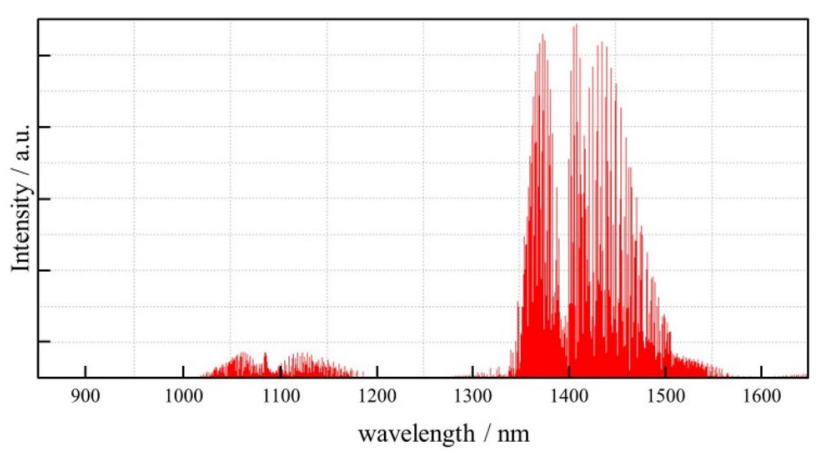

Fig. 5 Modeled near infrared emission lines for $\mathrm{H}_{2} \mathrm{O}$ at a temperature of $1800 \mathrm{~K}$ and ambient pressure using the molecular spectroscopic database HITRAN [5] and HITEMP [6] within the visible portion of the plume emission spectrum. Therefore, it was used as an indicator for a stable combustion. On the other hand, its use also guaranteed independence from density changes in the exhaust plume during the measurement, by comparing it with the backscattered signal. The test sequence with the shortest firing times $(10 \mathrm{~ms})$ showed the highest ratio, indicating a strong laser beam scattering. Assuming a slightly different injection time of MMH and NTO, the combustion was not ignited completely at the time of measurement, and thus a high amount of unburnt propellant droplets could be found in the plume. However, reducing the pulse repetition rate (increasing the combustion duration) resulted in lower ratios of backscattered to emission signals. The test run with the thruster operating in a steady state mode (nonpulsed) showed only negligible signal of the backscattered laser beam.

Mie scattering on droplets of the exhaust plume was modelled using the Mie scattering calculator of S. Prahl and S. Jacques [9]. Assuming a droplet size of a Sauter mean diameter of $1 \mu \mathrm{m}[7,8]$, and a concentration of 0.1 particles per $\mu \mathrm{m}^{3}$, laser beams of all three relevant wavelengths tend to be scattered in forward direction within the exhaust plume. However, as depicted in Fig. 9, the amount of light that is scattered in backward direction is wavelength dependent. Nevertheless, a non-polarized beam will be scattered on the unburned droplets of the plume in all directions and strongly angle dependent. Regarding a backscatter angle of $360^{\circ}$ photons with a wavelength of $\lambda=1064 \mathrm{~nm}$ appear five times weaker than photons of $\lambda=1550 \mathrm{~nm}$. In general, photons with the latter wavelength appear to be backscattered more intense than those with the former wavelength.

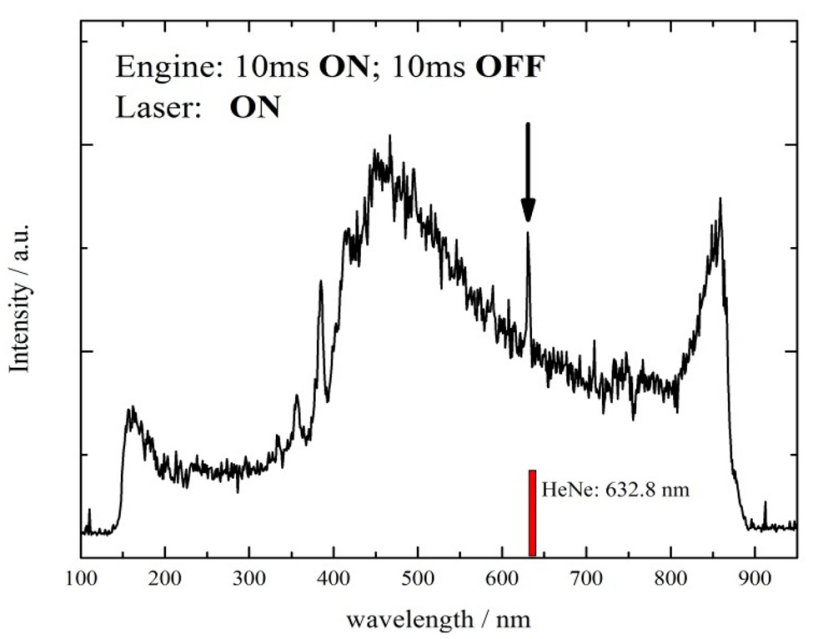

Fig. 6 Plume emission spectrum with the laser beam switched on and the $22 \mathrm{~N}$ thruster firing in pulse mode with $10 \mathrm{~ms}$ intervals. The $\mathrm{O}_{2}$ emission band at $384 \mathrm{~nm}$ is only slightly developed. At $632.8 \mathrm{~nm}$, the backscattered laser signal appears clearly 


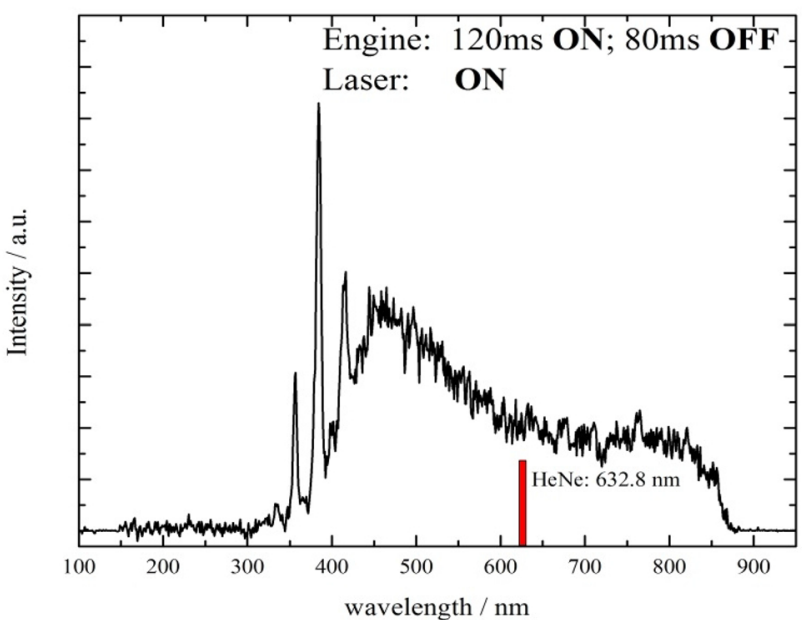

Fig. 7 Plume emission spectrum with the laser source crossing the exhaust gas. The $22 \mathrm{~N}$ thruster is firing in pulse mode with alternating $120 \mathrm{~ms}$ switched on and $80 \mathrm{~ms}$ switched off. The emission bands of $\mathrm{O}_{2}, \mathrm{CO}_{2}$ and $\mathrm{CN}$ at $355 \mathrm{~nm}, 384 \mathrm{~nm}$ and $415 \mathrm{~nm}$, respectively, are clearly pronounced, yet no trace of a backscattered signal of the $\mathrm{HeNe}$ laser source is visible

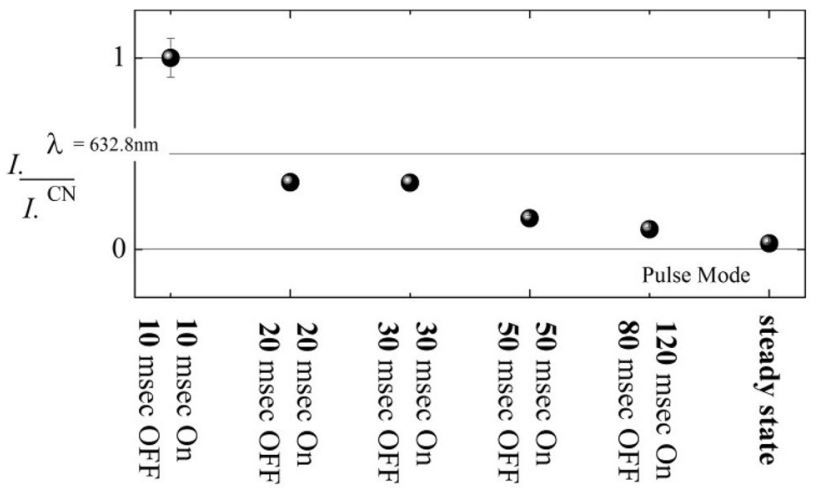

Fig. 8 Normalized intensity ratios of the backscattered laser signal at $\lambda=632.8 \mathrm{~nm}$ and the $\mathrm{CN}$ emission band at $384 \mathrm{~nm}$ as a function of the pulse duration in the $22 \mathrm{~N}$ thruster. Only at steady state conditions, the laser photons can be neglected almost entirely. The shorter the pulse duration, the more intense the backscattered signals and the less pronounced the emission of the combustion process

In Fig. 9, the deflection behavior of all three relevant wavelengths is depicted taking into account the theory of Mie scattering since the size of the ejected particles is within the range of the photon wavelength.

For all wavelengths tested, most of the light is scattered in forward direction, with a tendency to broaden the angle of deflection the longer the photon wavelength is. The highest possibility for the light to be backscattered is thus for $\lambda=1550 \mathrm{~nm}$. Furthermore, Fig. 9 shows the angular intensity distribution for three different polarizations of the incoming light relative to the output axis: parallel, perpendicular, and a composition of both (natural). As expected, only the light scattered from a perpendicularly polarized beam can occur with zero intensity at certain angles.

\section{Conclusion}

Several optical effects that impair Lidar performance in the vicinity of a pulsed exhaust plume of a LunarLander application were investigated.

The hot exhaust gas of a $22 \mathrm{~N}$ thruster was used to investigate the Mie scattering behavior of photons with $\lambda=632.8 \mathrm{~nm}$. Under near vacuum $\left(p=10^{-6}\right.$ bar at $\left.t_{0}\right)$ conditions, the thruster engine runs in different pulse modes and continuously in steady state. The shortest pulse mode consisted of alternating $10 \mathrm{~ms}$ firing time and $10 \mathrm{~ms}$ of idle time. These sequences showed the most intense backscattering signals and the least optical flame emission. On the other hand, observations of steady thruster firing showed only negligible backscattering yet the most intense optical flame emission. It is suggested that the photons of the laser beam were scattered in all directions on the unburned propellant droplets. Calculations using the Mie scattering calculator of S. Prahl and S. Jacques [9] showed the backscattering characteristics accordingly. It can therefore be concluded that LIDAR performance can be impaired by pulse durations of less than $50 \mathrm{~ms}$. It is therefore recommended to operate the thrusters in a steady mode or with pulse durations longer than $50 \mathrm{~ms}$ to avoid light scattering on unburned particles of the plume. Furthermore, it has been shown that photons with longer wavelengths are scattered away on unburned particles with a higher intensity than photons with shorter wavelength. Hence, the laser beam with the shortest wavelength $(\lambda=1064 \mathrm{~nm})$ should be preferred to reduce beam attenuation by Mie scattering.

The second test was conducted to evaluate possible interferences from absorption and flame emission of the plume in the near infrared regime. No interfering emission bands were observed for the planned LIDAR wavelengths $\lambda=1064 \mathrm{~nm}$ and $1550 \mathrm{~nm}$. Absorption can also be excluded for these wavelengths. However, the spectrum reveals broad $\mathrm{H}_{2} \mathrm{O}$ emission bands around the potential laser wavelength of $\lambda=1550 \mathrm{~nm}$. On the other hand, the range around the second laser wavelength $(\lambda=1064 \mathrm{~nm})$ that is considered for the LIDAR system appears relatively undisturbed. The Nd:YAG wavelength of $\lambda=1064 \mathrm{~nm}$ is thus to be preferred when operating in the vicinity of a hypergolic exhaust plume.

Moreover, the intense molecular emission lines of the visible spectrum could be used as a measure of thruster performance control and for health monitoring on the LunarLander application. 


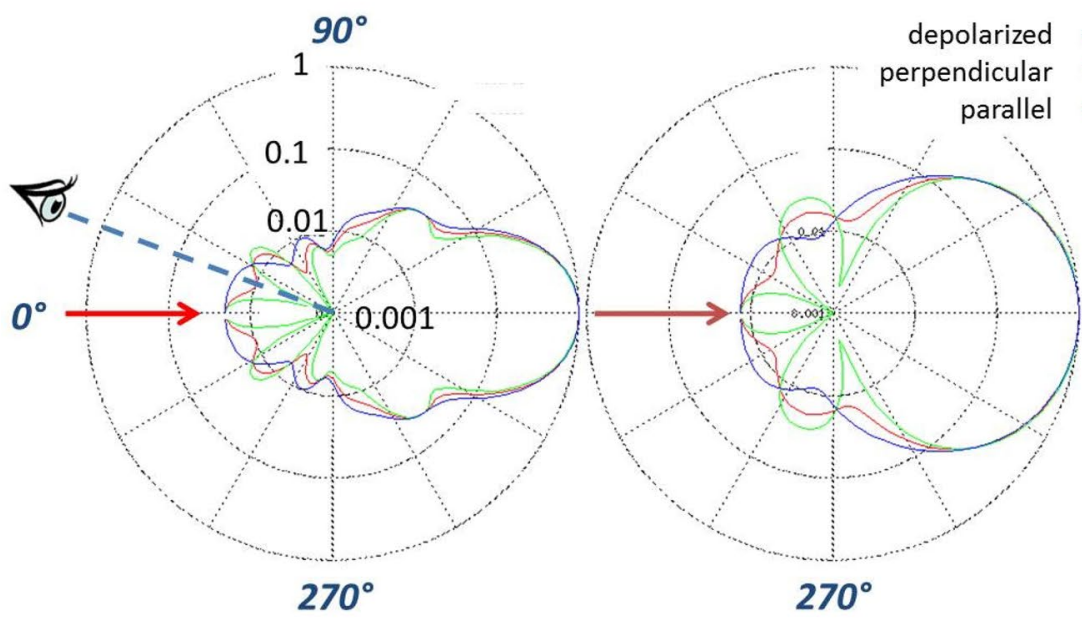

$\lambda=632.8 \mathrm{~nm}$
$1064 \mathrm{~nm}$

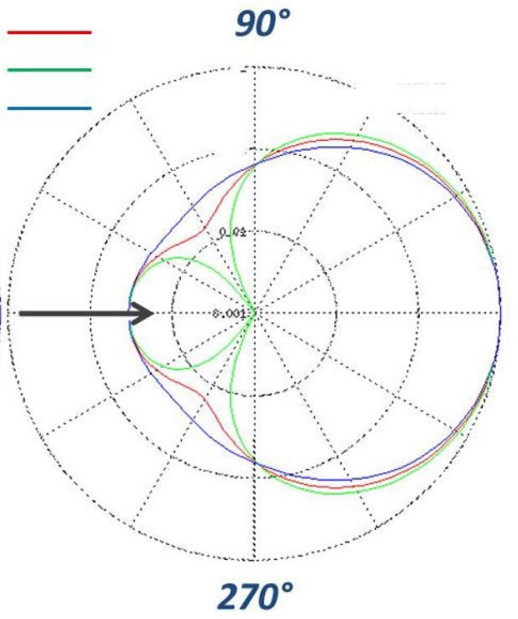

$180^{\circ}$
Fig. 9 Angle-dependent Mie scattering patterns for Lidar-relevant laser wavelengths. Arrows indicate the incident laser beam. All calculations are carried out assuming a spray of droplets with a Sauter mean diameter of $1 \mu \mathrm{m}$ [7] and a concentration of 0.1 particles per $\mu \mathrm{m}^{3}$. Furthermore, the angular intensity distribution is shown for

Acknowledgements Open Access funding provided by Projekt DEAL.

Open Access This article is licensed under a Creative Commons Attribution 4.0 International License, which permits use, sharing, adaptation, distribution and reproduction in any medium or format, as long as you give appropriate credit to the original author(s) and the source, provide a link to the Creative Commons licence, and indicate if changes were made. The images or other third party material in this article are included in the article's Creative Commons licence, unless indicated otherwise in a credit line to the material. If material is not included in the article's Creative Commons licence and your intended use is not permitted by statutory regulation or exceeds the permitted use, you will need to obtain permission directly from the copyright holder. To view a copy of this licence, visit http://creativecommons.org/licenses/by/4.0/.

\section{References}

1. Kraus, S., Wolf, M., Deck, J., Dargies, E., Gotzig, U.: In: 7th Space Propulsion Conference (2012)

2. Nonnenberg, C., Frank, I., Klapötke, T.M.: Ultrafast cold reactions in the bipropellant monomethylhydrazine/nitrogen tetroxide: CPMD simulations. Angew. Chemie Int. Ed. 43, 4585-4598 (2004)

3. Catoire, L., Chaumeix, N., Paillard, C.: Chemical kinetic model for monomethylhydrazine/nitrogen tetroxide gas phase combustion and hypergolic ignition. J. Propuls. Power 20, 87-92 (2004)

4. Lecourt, R., d'Herbigny, F.-X.: MMH/NTO injection and ignition in vacuum downstream from an Aestus engine single injection element. Aerosp. Sci. Technol. 8, 207-217 (2004)

5. Rothman, L.S., Gordon, I.E., Barbe, A., Benner, D.C., Bernath, P.F., Birk, M., Boudon, V., Brown, L.R., Campargue, A., Champion, J.-P., Chance, K., Coudert, L.H., Dana, V., Devi, V.M., Fally, S., Flaud, J.-M., Gamache, R.R., Goldman, A., Jacquemart, D., Kleiner, I., Lacome, N., Lafferty, W.J., Mandin, J.-Y., Massie, S.T., Mikhailenko, S.N., Miller, C.E., three different polarizations of the incoming light relative to the output axis: parallel (blue), perpendicular (green), and depolarized (red). For light scattering experiments $(\lambda=632.8 \mathrm{~nm})$, the spectrograph collected light from an angle of $20^{\circ}$ relative to the laser axis

Moazzen-Ahmadi, N., Naumenko, O.V., Nikitin, A.V., Orphal, J., Perevalov, V.I., Perrin, A., Predoi-Cross, A., Rinsland, C.P., Rotger, M., Šimečková, M., Smith, M.A.H., Sung, K., Tashkun, S.A., Tennyson, J., Toth, R.A., Vandaele, A.C., Vander Auwera, J., The, H.I.T.R.A.N.: molecular spectroscopic database. J. Quant. Spectrosc. Radiat. Transfer 110(2009), 533-572 (2008)

6. Rothman, L.S., Gordon, I.E., Barber, R.J., Dothe, H., Gamache, R.R., Goldman, A., Perevalov, V., Tashkun, S.A., Tennyson, J.: HITEMP, the high-temperature molecular spectroscopic database. J. Quant. Spectrosc. Radiat. Transfer 111, 2139-2150 (2010)

7. Lecourt, R., Barricau, P., Steelant, J.: Spray Velocity and Drop Size Measurements in Vacuum Conditions; In: ILASS Americas, 20th Annual Conference on Liquid Atomization and Spray Systems, Chicago, IL (2007)

8. Rees, A., Araneo, L., Salzmann, H., Kurudzija, E., Suslov, D., Lamanna, G., Sender, J., Oschwald, M.: Investigation of Velocity and Droplet Size Distribution of Flash Boiling LN2-Jets With Phase Doppler Anemometry; In: ILASS Europe, 29th Conference on Liquid Atomization and Spray Systems, Paris, France, (2019)

9. Prahl, S.: The Mie Scattering Calculation Program (2012)

10. Clapp, M.L., Miller, R.E.: Complex refractive indices of crystalline hydrazine from aerosol extinction spectra. Icarus $\mathbf{1 2 3}$, 396-403 (1996)

11. Sallah, M., Degheidy, A.R., Shaaban, S.M.: Polarized-radiation transfer in atmospheric aggragates using the Mie-Rayleigh limit. Appl. Math. Model. 40, 3561-3572 (2016)

12. Brown, A.J.: Spectral bluing induced by small particles under the Mie and Rayleigh regimes. Icarus 239, 85-95 (2014)

13. R. Stützer, S. Bublies, S. Kraus, M. Oschwald.: Optical investigation on the hypergolic MMH/NTO combustion in spacecraft propulsion. In: $5^{\text {th }}$ EUCASS (2013)

14. Gaydon, A.G.: The spectroscopy of flames, 2nd ed., chapter vii; Chapman \& Hall ltd., London (1974)

15. Davison, W.R., Carstens, J.P.: Pyrodynamics 2, 257-304 (1965)

Publisher's Note Springer Nature remains neutral with regard to jurisdictional claims in published maps and institutional affiliations. 